Article

\title{
Poloxamer 338 Affects Cell Adhesion and Biofilm Formation in Escherichia coli: Potential Applications in the Management of Catheter-Associated Urinary Tract Infections
}

\author{
Mariarita Stirpe ${ }^{1}$, Benedetta Brugnoli ${ }^{2}$, Gianfranco Donelli ${ }^{1}$, Iolanda Francolini ${ }^{2, *,+}$ (i) \\ and Claudia Vuotto $1, *,+$ \\ 1 Microbial Biofilm Laboratory, IRCCS Fondazione Santa Lucia, 00143 Rome, Italy; \\ mariaritastirpe@gmail.com (M.S.); g.donelli@hsantalucia.it (G.D.) \\ 2 Department of Chemistry, Sapienza University of Rome, 00185 Rome, Italy; benedettabrugnoli@hotmail.com \\ * Correspondence: iolanda.francolini@uniroma1.it (I.F.); c.vuotto@hsantalucia.it (C.V.) \\ + These authors contributed equally and should be regarded as co-last authors.
}

Received: 18 September 2020; Accepted: 23 October 2020; Published: 25 October 2020

\begin{abstract}
Poloxamers are nontoxic, amphiphilic copolymers used in different formulations. Due to its surfactant properties, Poloxamer 338 (P388) is herein proposed as a strategy to avoid biofilm formation often causing recalcitrant catheter-associated urinary tract infections (CAUTI). The aim is to evaluate the ability of P388 coatings to affect the adhesion of Ec5FSL and Ec9FSL Escherichia coli strains on silicone urinary catheters. Attenuated total reflection infrared spectroscopy, atomic force microscopy, and static water contact angle measurement were employed to characterize the P388-coated silicone catheter in terms of amount of P388 layered, coating thickness, homogeneity, and hydrophilicity. In static conditions, the antifouling power of P388 was defined by comparing the $E$. coli cells adherent on a hydrophilic P388-adsorbed catheter segment with those on an uncoated one. A P388-coated catheter, having a homogeneous coverage of $35 \mathrm{~nm}$ in thickness, reduced of $0.83 \log _{10}$ and $0.51 \log _{10}$ the biofilm of Ec5FSL and Ec9FSL, respectively. In dynamic conditions, the percentage of cell adhesion on P388-adsorbed silicone channels was investigated by a microfluidic system, simulating the in vivo conditions of catheterized patients. As a result, both E. coli isolates were undetected. The strong and stable antifouling property against $E$. coli biofilm lead us to consider P388 as a promising anti-biofilm agent for CAUTIs control.
\end{abstract}

Keywords: poloxamer 338; biofilm; urinary catheter; Escherichia coli; antifouling coatings

\section{Introduction}

Some of the most common infections acquired in both acute care hospitals and post-acute healthcare settings, such as the rehabilitation units, are the urinary tract infections (UTIs), representing around $40 \%$ of healthcare-associated infections (HAIs) [1] and being attributable for around $75 \%$ to use of an indwelling urinary catheter [2]. The most important risk factor for developing catheter-associated urinary tract infections (CAUTIs) is the prolonged use of an indwelling catheter, followed by female sex, diabetes mellitus, catheter insertion outside the operating room, and a breach in the closed system of catheter drainage [3]. In fact, it is now certain that the longer the catheter is in place, the higher the incidence of UTI. A number of diseases require long-term bladder catheterization, both those related to acute pathologies that have damaged the bladder, and those associated to chronic conditions, such as cerebrovascular accidents, spinal injury or neurological diseases, including Alzheimer, Parkinson, 
and Multiple Sclerosis, often causing an impaired emptying of the bladder (neurogenic bladder) and related ureteric reflux [4-6].

The bacterial species most frequently involved in CAUTIs are Escherichia coli [7], Proteus mirabilis, Enterococcus spp., Klebsiella pneumoniae, coagulase-negative Staphylococcus, Pseudomonas aeruginosa, Acinetobacter baumannii, and Candida spp. [8]. It is increasingly common, especially in hospitalized patients, to isolate from their urines multidrug- and extensively drug-resistant microorganisms, such as extended-spectrum beta-lactamase (ESBL)-producing bacteria, AmpC $\beta$-lactamases producers, and carbapenem-resistant Enterobacteriaceae [9-11].

The most important cause of CAUTI is the biofilm formation by these microorganisms along both interior and exterior catheter surfaces [12]. The establishment of biofilm communities on urinary catheters is considered the cause of chronic and recurrent UTIs, since they are able to bypass host defense mechanisms and tolerate antibiotic/antifungal therapies [13]. The resulting underestimated antimicrobial tolerance and the misuse of antibiotics trigger a vicious circle in which microorganisms acquire an even greater drug resistance.

No commercially available antibiotic has been demonstrated to be fully effective against bacteria grown as biofilm on urinary catheters. To overcome that, in the past few decades a great effort has been devoted to the development of safe, effective, and fast-acting anti-biofilm molecules and strategies that do not confer evolutionary pressure to microorganisms [14] as well as antifouling and antimicrobial coatings for medical devices, such as urinary catheters, for the purpose of improving their long-term and broad-spectrum efficacy, and biocompatibility [15].

Poloxamers are inert amphiphilic tri-block copolymers [poly(ethylene oxide)-block-poly(propylene oxide)-block-poly(propylene oxide) (PEO-PPO-PEO)] reported as suitable compounds for wound dressing, with a number of papers exploring the use and mode of action of mostly Poloxamer 188 (Pluronic F-68) and Poloxamer 407 (Pluronic F-127) in the enhancement of wound healing and their effect on biofilms [16]. Poloxamer ability to promote wound healing has been attributed to several factors including wound cleansing, suppressing protein aggregation, repairing tissue or cell membranes, and exerting intrinsic antimicrobial activity [17]. Poloxamer 407 was also employed to stabilize silver nanoparticles and develop formulations for skin wounds' care [18].

Nevertheless, it has been demonstrated that when applied to hydrophobic surfaces, such as silicone, poloxamers can self-assemble at the water/surface interface in a brush-like configuration, where the hydrophobic polypropylene oxide (PPO) block anchors to the surface while the hydrophilic polyethylene oxide (PEO) chains dangle in the adjacent solution, drastically reducing the nonspecific proteins adsorption [19] and bacterial adhesion [20]. Indeed, the hydrophilic PEO is considered the gold standard for antifouling applications, its repelling activity being related to hydration and steric hindrance effects [21].

In this study, a different type of poloxamer, Poloxamer 338 (P388), was chosen as potential antifouling coating for urinary catheters, because of its high PEO content $(80 \%)$ that results in an HLB (hydrophilic-lipophilic balance) higher than that of the commonly employed surfactant Pluronic F127 [22]. Specifically, P388 was adsorbed onto both silicone urinary catheters and silicone tubes comparable to urinary catheters, in order to evaluate the anti-biofilm efficacy against $E$. coli strains in static and dynamic conditions, respectively.

\section{Results}

In this study, the efficacy of the P388 poloxamer (Figure 1) as antifouling coating for silicone urinary catheters was investigated against biofilm-forming E. coli strains causing CAUTIs. Among the different available poloxamers, differing in terms of PPO units (ranging from 16 to 69) and molecular weight (ranging from 1850 to 14,600), P388 (also known as F108) was chosen because it possesses a significantly high number of PPO units (ca. 50) and the highest molecular weight $(14,600)$. 


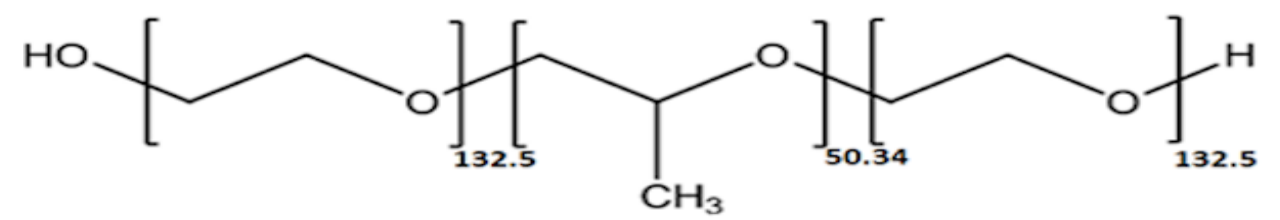

Figure 1. Chemical structure of Poloxamer 388 (P388). The P388 is a nontoxic, amphiphilic triblock copolymer composed of a central hydrophobic chain of poly (propylene oxide) flanked by two hydrophilic chains of poly (ethylene oxide).

The potential antifouling ability of P388 was investigated in both static and flow conditions. In particular, the static conditions in an open model allowed us to fully characterize the chemical properties of the P388-modified silicone surfaces, while the flow conditions applied in the Bioflux system permitted to study biofilm formation under a shear rate that is a typical condition in urinary catheterization.

The adsorption grade of $\mathrm{P} 388$, at concentrations ranging from 5 to $60 \mathrm{mg} / \mathrm{mL}$, onto $1 \mathrm{~cm}$ long segment of silicone catheter was determined by Attenuated Total Reflection Infrared Spectroscopy (ATR-IR) analysis of the P388 solutions before and after contact with catheter. In Figure 2A, the ATR-IR spectrum of the P388 solution at $30 \mathrm{mg} / \mathrm{mL}$ is reported. In the spectrum, the adsorption peaks of water (stretching at ca. $3200 \mathrm{~cm}^{-1}$ and bending at ca. $1600 \mathrm{~cm}^{-1}$ ) and a peak centered at $1078 \mathrm{~cm}^{-1}$, related to the $\mathrm{C}-\mathrm{O}-\mathrm{C}$ stretching of $\mathrm{PEO}$ and $\mathrm{PPO}$ units, are present. This latter peak is more evident in the subtraction spectrum reported in Figure 2A, obtained by subtracting the spectrum of $\mathrm{H}_{2} \mathrm{O}$ to the spectrum of the P388 $30 \mathrm{mg} / \mathrm{mL}$ solution. In Figure 2B, the spectra of three selected P388 solution concentrations $(10,20$, and $30 \mathrm{mg} / \mathrm{mL})$ in the $1200-1000 \mathrm{~cm}-1$ spectral range are reported.
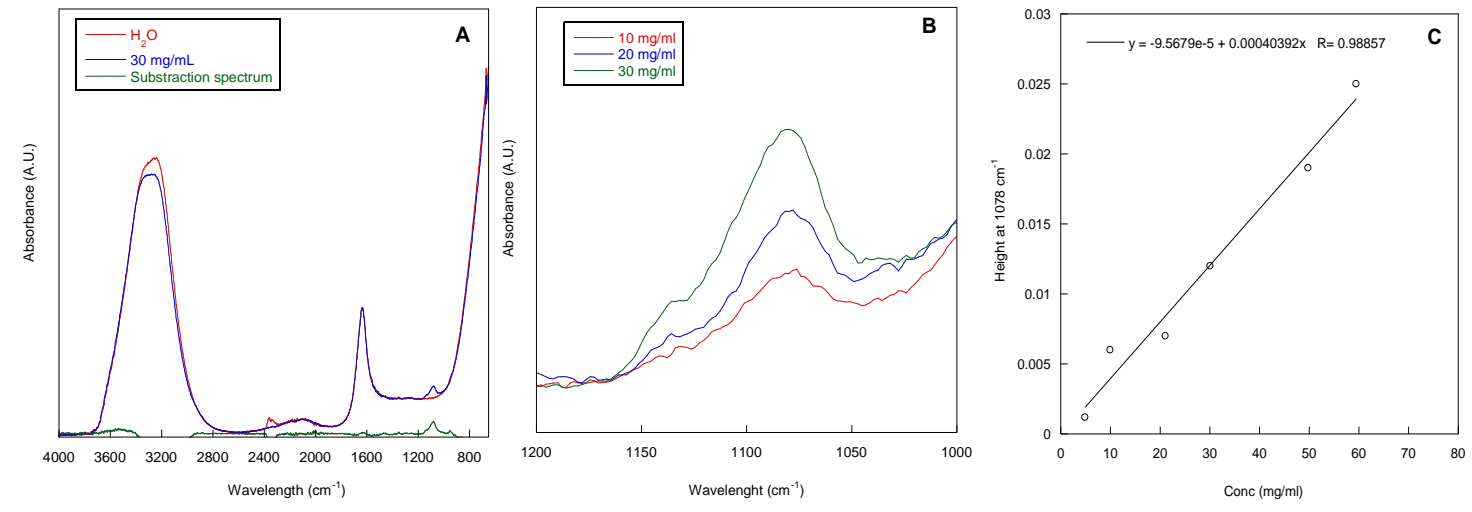

Figure 2. ATR-IR spectra. ATR-IR spectra of water, $\mathrm{P} 388$ water solution at $30 \mathrm{mg} / \mathrm{mL}$ and the relative subtraction spectrum (A). ATR-IR spectra of P388 water solution at different concentrations in the $1200-1000 \mathrm{~cm}^{-1}$ spectral range (B). Calibration curve peak height at $1078 \mathrm{~cm}^{-1}$ vs. P388 concentration (C).

As it can be observed, the intensity of the peak at $1078 \mathrm{~cm}^{-1}$ increased with P388 solution concentration. This is in accordance with the Lambert-Beer equation $(A=\varepsilon \times c \times l$; where $A$ is the absorbance at the chosen wavelength, $c$ is concentration of the sample, $\varepsilon$ the molar extinction coefficient, and $l$ is the optical length that in our case corresponds to the beam penetration depth). Therefore, a calibration curve height of the peak at $1078 \mathrm{~cm}^{-1}$ vs. concentration was obtained with a good correlation coefficient (R) (Figure 2C). Such a curve was used to determine the unknown P388 concentration after contact with the segment of silicone catheter to be subtracted from the solution concentration before catheter contact.

In Figure 3, P388-adsorbed amounts, expressed as mg per surface unit $\left(\mathrm{cm}^{2}\right)$, are reported as a function of P388 concentration and time of adsorption. 


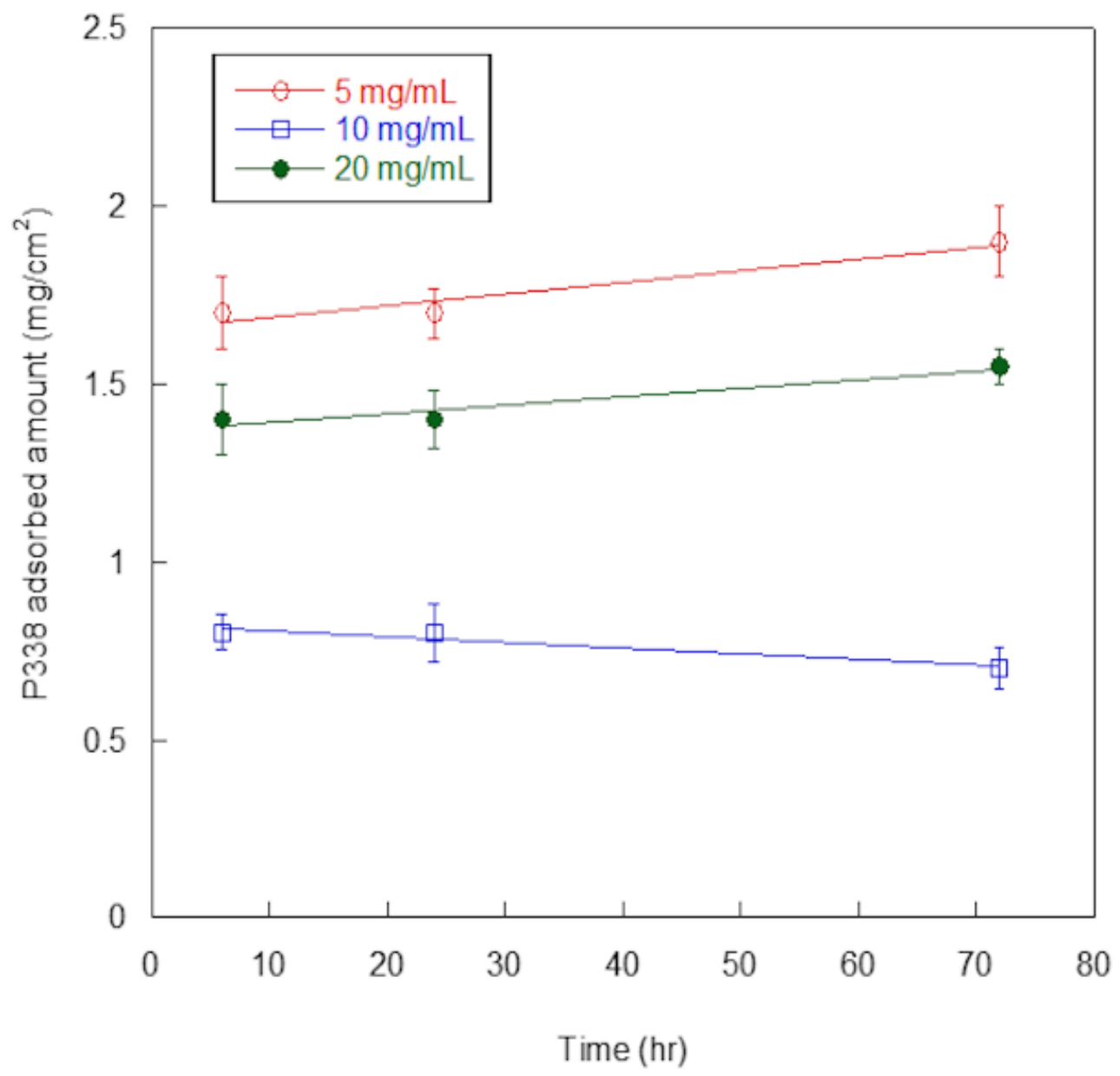

Figure 3. P388 adsorption on silicone. Quantification of P388 adsorbed per surface unit $\left(\mathrm{cm}^{2}\right)$ of silicone catheter. Results are expressed as means \pm standard deviations of three independent experiments.

At all of the explored concentrations $(5,10$, and $20 \mathrm{mg} / \mathrm{mL})$, adsorbed P388 amount was similar at $6 \mathrm{~h}$ and $24 \mathrm{~h}$, and increased only slightly at $72 \mathrm{~h}$, except for $10 \mathrm{mg} / \mathrm{mL}$ concentration. Such finding suggested the adsorption was fast so that the maximum adsorption was already reached at $6 \mathrm{~h}$. Additionally, at any time of adsorption $(6,24$, or $72 \mathrm{~h})$, the highest adsorption amounts were obtained at $5 \mathrm{mg} / \mathrm{mL}$ P388 concentration. Presumably, the desorption process competed with the adsorption one at higher $\mathrm{P} 388$ concentrations.

For these reasons, we decided to use $5 \mathrm{mg} / \mathrm{mL}(0.5 \%)$ as working concentration of P388 and $6 \mathrm{~h}$ as adsorption time for further characterization and experiments. In these conditions, the P388-adsorbed amount was $1.7 \pm 0.2 \mathrm{mg} / \mathrm{cm}^{2}$, that is $18.7 \%$ of the P388 amount available for adsorption.

In Figure 4, the Atomic Force Microscopy (AFM) image and the thickness profile of the P388 catheter coating obtained at $5 \mathrm{mg} / \mathrm{mL}$ P38 concentration are reported. The black path present in the image is the one done by scratching the surface with a needle. As it can be observed, the coating is homogeneous and with a thickness of ca. $35 \mathrm{~nm}$ (Figure 4B). 

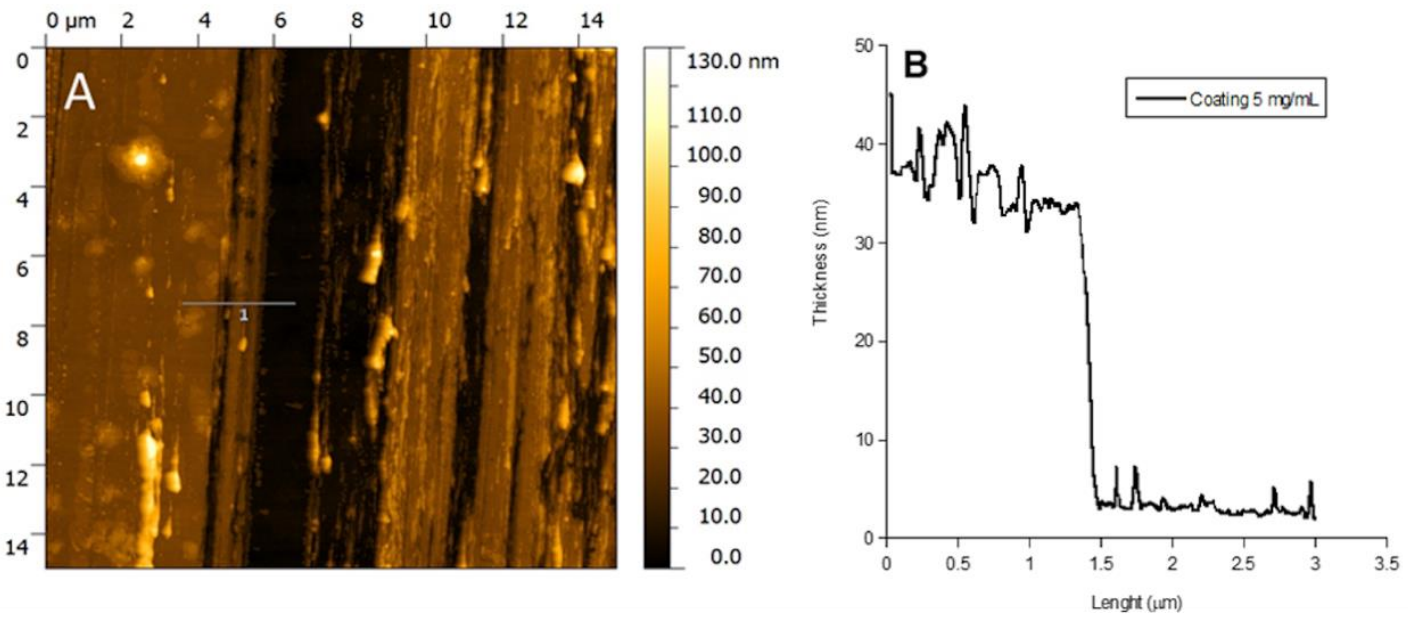

Figure 4. AFM analysis. AFM image of P388 coating obtained at $5 \mathrm{mg} / \mathrm{mL}$ P388 concentration (A) and coating height profile at the same concentration (B).

The contact angle of the uncoated and coated catheter surfaces was also evaluated in order to gain information about surface wettability before and after coating. Indeed, surface hydrophilicity is known to strongly affect bacterial adhesion and biofilm formation. The uncoated catheter had a contact angle $\left(\theta^{\circ}\right)$ of $95^{\circ} \pm 5$, confirming the hydrophobicity of the silicone surface, while catheters exposed to P388 solutions at $5 \mathrm{mg} / \mathrm{mL}$ for $6 \mathrm{~h}$ showed a contact angle of $72^{\circ} \pm 3$, suggesting the exposure of the PEO hydrophilic chains at the water/surface interface. It is then possible to speculate that the adsorbed P388 was in a brush-like configuration promoted by the high hydrophobicity of silicone [23]. The brush-like configuration is the preferred one for our purposes since the hydrophilic PEO brushes could hinder bacterial adhesion by hydration and steric hindrance effects [24].

The two E. coli isolates (Ec5FSL and Ec9FSL) to be tested were selected on the basis of the antibiotic resistance profile and the biofilm-forming ability.

Looking at the antibiotic resistance profile, the Ec5FSL isolate was classified as susceptible (S), being susceptible to all the tested classes of antibiotics; while Ec9FSL was considered multidrug-resistant (MDR), since the isolate was nonsusceptible to at least one agent in $\geq 3$ antimicrobial categories (fluoroquinolones, penicillins, third-generation cephalosporins, fourth-generation cephalosporin).

Regarding the phenotypic characterization, Ec5FSL isolate was classified as strongly adherent on polystyrene 96-well plate while Ec9FSL isolate as moderately adherent (Figure 5A). The results were also expressed as Optical Density (OD) 570 per surface unit $\left(\mathrm{cm}^{2}\right)$ (Figure $\left.5 \mathrm{~B}\right)$.
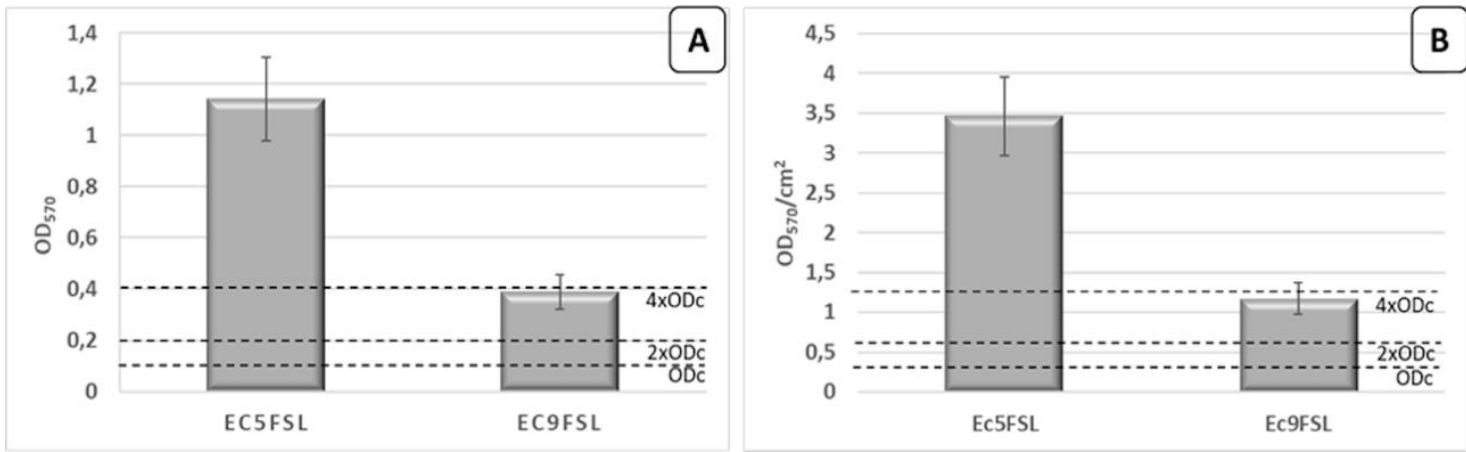

Figure 5. Biofilm production assay. Quantification of Ec5FSL and Ec9FSL biofilms formed after $20 \mathrm{~h}$ incubation on 96-well plates, expressed as $\mathrm{OD}_{570}(\mathbf{A})$ and taking into consideration the cell growth area of each well $\left(0.33 \mathrm{~cm}^{2}\right)(\mathbf{B})$. Results are expressed as means \pm standard deviations of three independent experiments. 
The Ec5FSL susceptible isolate was more able to grow as biofilm with respect to the MDR one, this possibly being a compensation method to enhance its long-term survival within the host.

To determine a possible growth inhibition activity of this molecule, the two isolates were grown in presence of P388 solution at $5 \mathrm{mg} / \mathrm{mL}$ concentration (Figure 6). P388 did not have significant intrinsic activity against the two tested strains (Figure 6).

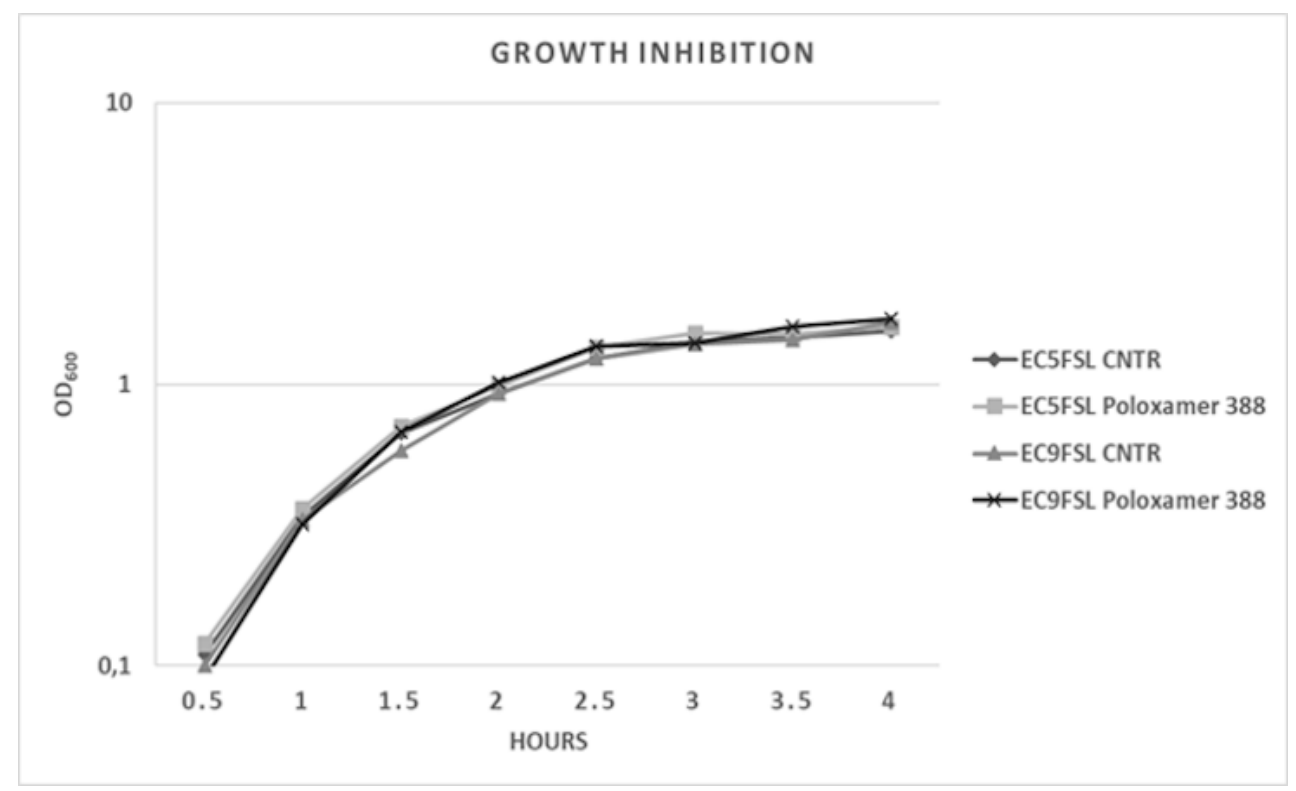

Figure 6. E. coli growth kinetics against P388. Growth curves of Ec5FSL and Ec9FSL alone and in presence of P388. Absorbance unit is on a logarithmic scale.

The antifouling activity of P388 was first assessed in static conditions, by adsorbing the molecule on a $1 \mathrm{~cm}$ segment of 100\% silicone catheter. Biofilms of Ec5FSL and Ec9FSL grown on pristine silicone catheter and P388-adsorbed silicone catheter were collected to determine the bacterial $\mathrm{CFU} / \mathrm{cm}^{2}$ on silicone catheter (Figure 7).

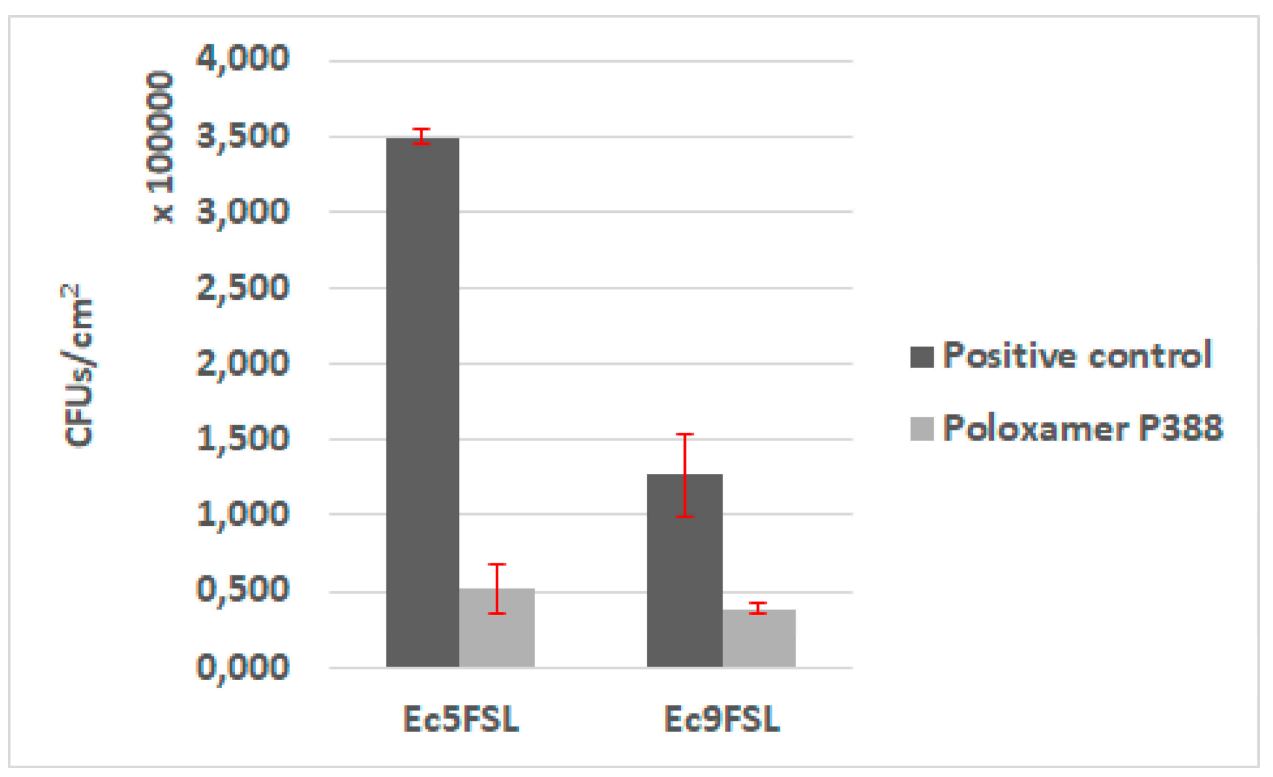

Figure 7. Antifouling activity of P388 in static conditions. CFU $/ \mathrm{cm}^{2}$ results of Ec5FSL and Ec9FSL biofilms formed on P388-adsorbed segment of silicone urinary catheter (Poloxamer 388) and on unadsorbed catheter (positive control). 
A statistically significant reduction of the cells adhered on P388-adsorbed catheter was detected in both isolates. The stronger evidence was observed in Ec5FSL with a $p$-value of 0.0003, while the reduction of Ec9FSL biofilm was $p$-value of 0.0022. Regardless, a 99\% level of statistical significance ( $p$-value $\leq 0.01)$ was determined for both of them. More specifically, about an $85 \%\left(0.83 \log _{10}\right)$ and $78 \%$ $\left(0.65 \log _{10}\right)$ reduction in CFU/cm² of Ec5FSL and Ec9FSL, respectively, compared with the untreated controls (100\%), was observed when P388 was absorbed onto silicone catheters (Figure 7).

The efficacy of P388 in reducing the E. coli adhesion on a silicone-made urinary catheter was further assessed by using a microfluidic apparatus (BioFlux System 200, Fluxion Biosciences, Inc., Alameda, CA, USA) that allows a dynamic biofilm analysis under controllable shear forces. To investigate the potential ability to interfere with the initial microbial adhesion process, P388 was adsorbed onto the silicone microfluidic flow channels arranged on a BioFlux well plate. In this way, the in vivo conditions of urinary catheters were mimicked in terms of both flow conditions and catheter material. As reported in the Materials and Methods section, P388 adsorption onto the silicone microfluidic flow channels was carried out by using a $5 \mathrm{mg} / \mathrm{mL}$ P388 concentration, that is, the concentration which gave the best results in static experiments. However, it should be considered that the maximum P388 solution volume able to fill the flow channel was significantly lower with respect to the volume used in static experiments (few microliters instead of $3 \mathrm{~mL}$ ), this meaning that, at the same starting concentration, the P388 amount (mg) available for adsorption to flow channel surface unit $\left(\mathrm{cm}^{2}\right)$ was only $0.03 \mathrm{mg} / \mathrm{cm}^{2}$ compared with $9.1 \mathrm{mg} / \mathrm{cm}^{2}$ of static experiments. The decision to keep $5 \mathrm{mg} / \mathrm{mL}$ P388 concentration arises from the fact that it would not have been possible in any case to reach in dynamic conditions a P388 availability of $9.1 \mathrm{mg} / \mathrm{cm}^{2}$ without exceeding the P388 critical micelle concentration. Therefore, even if not experimentally definable because of the closed system used which makes direct measurement impossible, we expect on the microfluidic flow channels a P388 coating significantly less concentrated than that obtained on the catheter segment. As shown in Figure 8, the P388 coating, although at very low concentrations, was able to protect the silicone surface from cell adhesion and biofilm formation by both Ec5FSL and Ec9FSL isolates. Indeed, as shown in Figure 8, biofilms of both strains achieved full surface coverage of uncoated silicone channels within $15 \mathrm{~h}$, while the cells adhesion forces were definitely low on P388-adsorbed silicone microfluidic tubes, they were enough to completely inhibit biofilm formation under shear forces.

In confirmation of the Bioflux micrographs, Figure 9 shows the Confocal Laser Scanning Microscopy (CLSM) images of the P338-adsorbed and unadsorbed channels obtained after live/dead staining. As can be seen, the only detectable biofilm was that formed within the unadsorbed channel (Figure 8A,B), whilst in P388-adsorbed channel it was only detectable a negligible amount of live/dead stain adsorbed by the silicone tube walls. 
A Unadsorbed channel-Ec5FSL P388-adsorbed channel-Ec5FSL
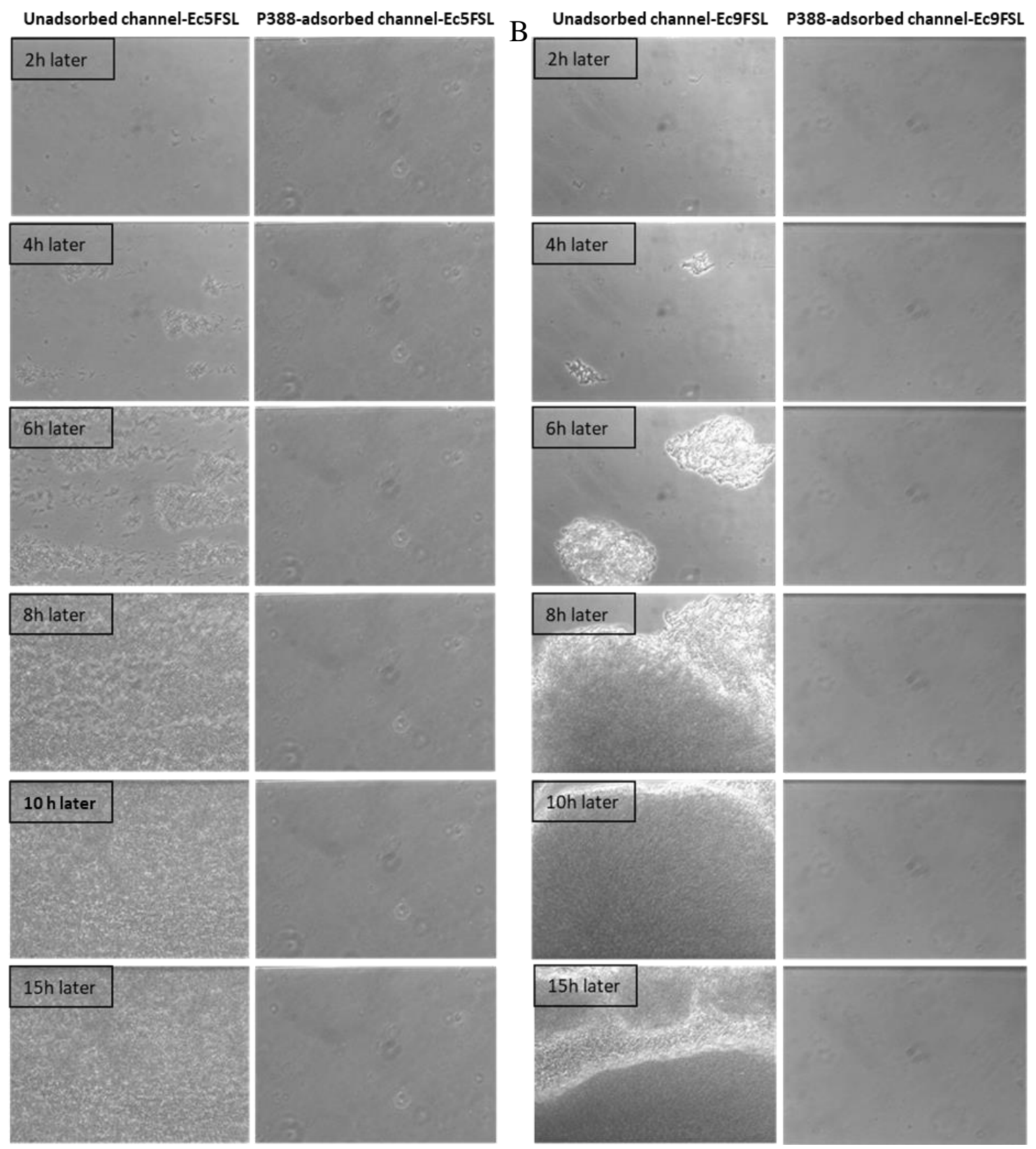

Figure 8. Antifouling activity of P388 in dynamic conditions. Bioflux micrographs taken at 20x objective magnification, at different time points, of Ec5FSL (A) and Ec9FSL (B) biofilm formation on unadsorbed (left side of semicolumn) or P388-adsorbed (right side of semicolumn) silicone channels after $15 \mathrm{~h}$ under a shear flow of $0.5 \mathrm{dyn} / \mathrm{cm}^{2}(0.05 \mathrm{~Pa})$.

As it can be inferred from the Table 1, as predictable, the area fraction covered by biofilm was nil for both Ec5FSL and Ec9FSL isolates with respect to their controls. 

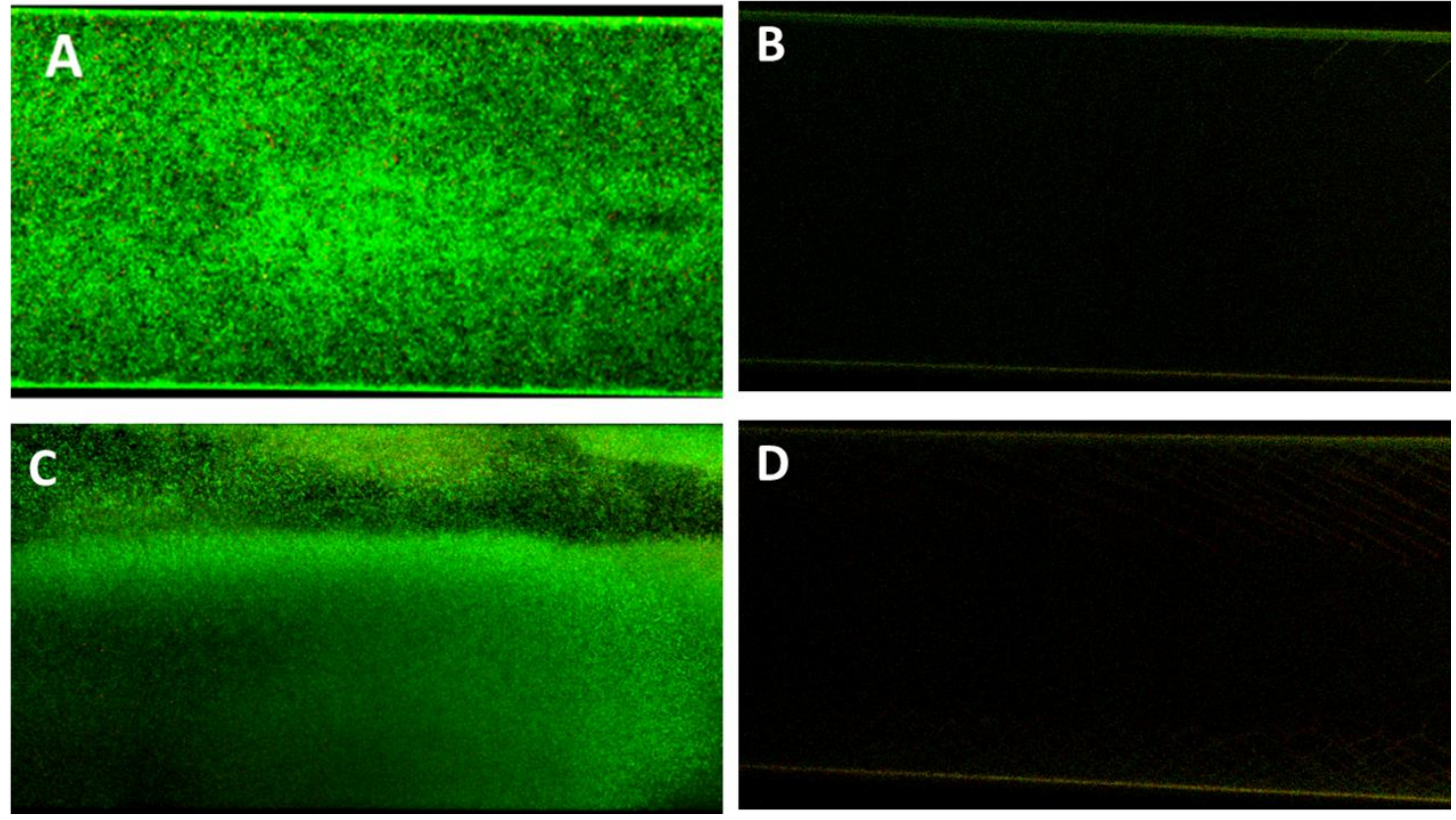

Figure 9. Antifouling activity of P388 in dynamic conditions. Representative CLSM images of Ec5FSL $(\mathbf{A}, \mathbf{B})$ and Ec9FSL (C,D) biofilms formed after $15 \mathrm{~h}$ under a shear flow of $0.5 \mathrm{dyn} / \mathrm{cm}^{2}(0.05 \mathrm{~Pa})$ on unadsorbed (A,C) and P388-adsorbed (B,D) microfluidic channel.

Table 1. Percentages of area fractions covered by total biofilm and biofilm area constituted by dead cells as mean values of at least four images for each sample.

\begin{tabular}{ccc}
\hline Treatment & $\begin{array}{c}\text { Area Fraction Covered by Biofilm with } \\
\text { Respect to } \mathbf{0 . 2 3 4} \mathbf{~ m m}^{\mathbf{2}}\end{array}$ & $\begin{array}{c}\text { \% of Biofilm Area Covered by } \\
\text { Dead Cells }\end{array}$ \\
\hline Unadsorbed channel inoculated with Ec5FSL & $88.88 \%$ & $7.87 \%$ \\
P388-adsorbed channel inoculated with Ec5FSL & $0 \%$ & $0 \%$ \\
Unadsorbed channel inoculated with Ec9FSL & $92.00 \%$ & $11.12 \%$ \\
P388-adsorbed channel inoculated with Ec9FSL & $0 \%$ & $0 \%$ \\
\hline
\end{tabular}

In addition, the area fraction was also nil when tests were carried out after a sterile LB washing step for $14 \mathrm{~h}$ under a shear flow of $0.5 \mathrm{dyn} / \mathrm{cm}^{2}$ within P388-adsorbed channel (data not shown since results were similar to Figure 8), this proving also the stability of the P388 adsorption on silicone surfaces related to the strong hydrophobic interactions between silicone and the PPO segment of P388.

P388 coating resulted to be also stable when artificial urine was used as flow and growing medium, by letting urine flow for $24 \mathrm{~h}$ inside the P338-adsorbed channel and then proceeding to inoculate the bacteria in the same medium (results comparable to Figure 8).

By analyzing the micrographs of the first adhesion steps for both isolates in the two conditions, it was possible to observe that the number of Ec5FSL and Ec9FSL cells able to adhere to the P388-coated surface within one hour was much lower than that of cells attached on the pristine silicone surface, and that once the flow was activated the cells were unable to remain adherent, being very loosely bound.

Interestingly, as side data, the Ec9FSL isolate showed a significant phenotypic variation and an increased ability to grow as biofilm in dynamic conditions (Figure 8) with respect to static ones (Figure 5), so reaching the Ec5FSL biofilm-forming ability. This finding can be explained with an induction of biofilm upon environmental stress, the fluid shear force possibly being an environmental signal for Ec9FSL biofilm formation. Thus, it can be hypothesized an important role of the catheter microenvironment, especially the fluid flow, in the biofilm establishment by some strains of MDR E. coli that are not intrinsically strong biofilm producers. 


\section{Discussion}

Nonionic, amphiphilic, tri-block copolymers, because of their amphiphilic structures, are known to be able to self-assemble in water at variable temperatures depending on polymer molecular weight and hydrophilic/hydrophobic molar ratio. The surfactant properties of poloxamers justify their large use as excipients in cosmetics and pharmaceuticals, where their use is considered safe with a rapid clearance from the body also when introduced via routes other than dermal exposure $[25,26]$. In particular, no maximum concentration of P338 use has been suggested in marketed mouthwashes and breath fresheners. Also, acute, short-term, sub chronic, and chronic animal testing suggested a low order of toxicity and little concern about carcinogenesis, with its use at 0.2 or $1.0 \mathrm{~g} / \mathrm{kg}$ day producing no adverse effects in dogs [26].

The use of poloxamers as antifouling compounds for indwelling medical devices is still little evaluated. In general, just a few studies have investigated the antiadhesive properties of nonchemically derivatized Poloxamer 188 and Poloxamer 407 onto poly methyl methacrylate (PMMA) [27], polystyrene (PE) [28,29], and silicone sheets [30,31]. A study also addressed the colonization of a Poloxamer 407-coated silicone rubber discs in an infected pocket in vivo, mimicking revision surgery after biomaterial-associated infection [32].

The search for nonbiocidal compounds able to counteract biofilm formation on indwelling medical devices, causing neither toxicity nor development of resistance, is increasingly being reported in the literature. In this study was demonstrated the nonbiocidal activity of Poloxamer 388, these results being comparable with those obtained by Veyries and co-workers [27] with Poloxamer 407 against staphylococci. On the contrary, Mycobacterium avium complex (MAC), having an outer glycolipid layer which protects the organisms from antibiotics and host defense mechanisms, was inhibited by Poloxamer 331, which retarded the growth of most isolates, presumably by disrupting the lipid barrier [33]. Thus, a species- and poloxamer-specific effect can be hypothesized. On the contrary, P388 was an effective antifouling agent for inhibiting biofilm growth of E. coli on hydrophobic surfaces even at much lower concentrations than those necessary by using other poloxamers, such as $20 \%$ Poloxamer-188 [31].

More specifically, a P388-coated silicone urinary catheter, well characterized in terms of amount of adsorbed P388, surface properties, layer thickness, surface coverage, and coating stability, was able to significantly reduce biofilm formation of both susceptible and multi-drug-resistant $E$. coli isolates in static conditions. This result confirms the well-known antifouling properties of polyethylene oxide, a hydrophilic macromolecule resistant to nonspecific adsorption of proteins and cells. The antifouling mechanism of PEO seems to be multifactorial and related to combined hydration and steric hindrance effects [34]. Specifically, due to its high hydrophilicity, PEO adsorption or binding to surfaces reduces the interfacial free energy, thus decreasing the driving force for nonspecific biofouling. Additionally, in aqueous environment, the hydration of PEO chains results in the formation of a water layer strongly bonded to the surface, which represent a barrier for proteins and bacteria approaching the surface. As for the steric hindrance effect, $\mathrm{Mu}$ and colleagues demonstrated by molecular modeling that onto PEGylated surfaces PEO chain remains highly flexible and can form a distinctive hydrated polymer layer [35]. The adsorption of proteins or bacteria onto such a layer would involve the compression of PEO chains, which is a not thermodynamically favorable process. This was further confirmed by measuring the interaction forces between bacteria and PEO-coated glass surface [35]. Specifically, it has been demonstrated the absence of long-range attractive forces and the presence of repulsive forces related to steric effects [36].

The experiments carried out under flow aimed at verifying the P388 antifouling properties in conditions better resembling those of urinary catheterization. We showed that P388-coated silicone surfaces were also strongly refractory to biofilm formation under flow. P388 coating resulted to be stable, confirming the strong hydrophobic interactions established between the hydrophobic silicone surface and the PPO segments of P388. As the only term of comparison in the literature, Nejadnik and colleagues [20] evaluated the efficacy, in dynamic conditions, of another poloxamer, Pluronic F-127, 
against Staphilococcus and Pseudomonas biofilms formed on silicone rubber sheets, and they observed only a delay in biofilm formation on brush-coatings with respect to pristine silicone rubber surface. However, it should be noted that, in addition to the poloxamers being different, the two systems are also not completely comparable because of the silicone rubber sheets allocated in chambers used by the authors instead of the silicone tube (with a flow inside) used in this study. Additionally, concentration, timing and shear flow were different, as they exposed the silicone rubber sheet to a solution of $0.05 \%$ of Pluronic F-127 for $20 \mathrm{~min}$ in the adsorption step and the experiment was carried out at $0.002 \mathrm{~Pa}$ [20].

The coating stability was maintained in artificial urine, its use as flow medium not affecting the antifouling efficacy of P388 coating. These results imply that PEO brushes over the surface avoided the formation of a conditioning film potentially able to reduce the efficacy. Without any doubt, the most satisfactory result was obtained under dynamic conditions, when a $100 \%$ efficacy was detected, although at even lower P388-adhered concentrations than those used for static experiments. The Bioflux allowed us to obtain totally reproducible and comparable results by using hydrodynamic conditions that mimic, at a microscale, phenomena occurring in the urinary system, combined with the use of plates having microfluidic channels made of the same material as the catheters.

\section{Materials and Methods}

\subsection{Materials and Bacterial Strains}

P388 (Merck), also named Pluronic F108, has a molecular weight (Mn) of 14,600 Da with a number of PPO unit of 50.34 and PEO unit of 265.45 [22].

E. coli Ec5FSL and Ec9FSL strains were collected from urines of catheterized patients suffering from CAUTI hospitalized at IRCCS Fondazione Santa Lucia (Rome, Italy), and identified by VITEK ${ }^{\circledR}$ 2 (bioMérieux Italia). VITEK ${ }^{\circledR} 2$ system was used for the antimicrobial susceptibility testing (AST) of Ec5FSL and Ec9FSL isolates, by performing automated Minimum Inhibitory Concentration (MIC) testing with Vitek2 card AST-N204, intended for use in the determination of antibiotic sensitivity of clinically relevant aerobic Gram-negative bacilli.

\subsection{Quantitative Biofilm Production Assay}

Ec5FSL and Ec9FSL isolates were grown overnight at $37^{\circ} \mathrm{C}$ in Luria-Bertani (LB) broth. Quantitative biofilm production assay was performed as described in Vuotto et al. [11]. Each plate was incubated for $20 \mathrm{~h}$ at $37^{\circ} \mathrm{C}$, and experiments were repeated three times.

\subsection{P388 Adsorption onto Silicone Tubes}

P388 was adsorbed onto cut lengthwise $1 \mathrm{~cm}$ long segments of a two-way Foley catheter (18 Fr) marketed by Unomedical (ConvaTec Company, Deeside, UK) by immersing each of them into $3 \mathrm{~mL}$ of P388 water solution at 5, 10 , or $20 \mathrm{mg} / \mathrm{mL}$ concentrations $\left(3.4 \times 10^{-4} \mathrm{M}, 6.8 \times 10^{-4} \mathrm{M}\right.$, and $1.4 \times 10^{-4} \mathrm{M}$, respectively) for 6,24 , and $72 \mathrm{~h}$. By considering the catheter segment size, the P388 amount available for adsorption to catheter surface unit at each P388 concentration was $9.1 \mathrm{mg} / \mathrm{cm}^{2}, 18.2 \mathrm{mg} / \mathrm{cm}^{2}$, and $36.4 \mathrm{mg} / \mathrm{cm}^{2}$ for 5,10 , and $20 \mathrm{mg} / \mathrm{mL}$, respectively. Following immersion, catheter segments were recovered and washed twice with PBS to remove the unadsorbed polymer. All the selected P388 concentrations were lower than polymer critical micelle concentration, which is $33.4 \mathrm{~g} / \mathrm{L}$ at $25^{\circ} \mathrm{C}$ [37].

\subsection{Determination of the Amount of Adsorbed P388}

The amount of adsorbed P388 was obtained by subtracting from the initial P388 concentration both the P388 amount still present in solution after the contact with cut lengthwise $1 \mathrm{~cm}$ segment of urinary catheter and the amount further detected in the washing solutions. To this aim, a novel analytical method based on ATR-IR (Nicolet 6700 spectrophotometer) technique was set up to determine P388 amount in solution. Specifically, a drop of P388 solution at concentration ranging from 5 to $60 \mathrm{mg} / \mathrm{mL}$ was poured over the surface of the ATR crystal, and ATR spectra were recorded in the 4000-650 nm 
wavelength range, at $2 \mathrm{~cm}^{-1}$ resolution and 200 accumulations. By assuming a constant refractive index for the different Poloxamer 388 concentrations, a calibration curve peak height at $1078 \mathrm{~cm}^{-1} \mathrm{vs}$. P388 concentration was obtained and used to determine unknown P388 amounts in solution.

\subsection{Evaluation of Morphology and Thickness of P388 Coatings}

The morphology and thickness of P388 coatings were evaluated by AFM. Specifically, for thickness evaluation, a scratch was done onto the surface of P388-coated samples by a needle in order to create a channel and measure thickness of the polymeric layer. AFM characterization was performed by using a Veeco AFM Multimode ${ }^{\mathrm{TM}}$ equipped with a Nanoscope IIIa controller. Images were obtained in tapping mode acquiring topography, amplitude and phase data, by using a RTESP Bruker tip (nominal parameters $\mathrm{r}=8 \mathrm{~mm}, \mathrm{f}=300 \mathrm{kHz}, \mathrm{k}=40 \mathrm{~N} / \mathrm{m}$ ) and with a $512 \times 512$ pixels resolution. Images were then corrected by polynomial background filters using the software Gwyddion 2.31.

\subsection{Static Contact Angle}

To examine catheter wettability before and after P388 coating, the static water contact angle was measured at room temperature by the drop method. Specifically, a water droplet (Milli-Q water) was deposited on the catheter surface, and a picture was taken. Since the catheter has a curved surface, image processing, spline fitting, and numerical integration were used to extract the drop contour in a number of cross-sections so to determine the drop contact angle at the equilibrium, according to the method developed by Guilizzoni [38]. The obtained images were elaborated with the SigmaPlot software (Systat Software Inc., San Jose, CA, USA). The reported contact angle was the mean value of five measurements.

\subsection{E. coli Growth Inhibition Assay in Presence of P388}

Overnight inocula of E. coli Ec5FSL and Ec9FSL strains in LB broth were adjusted to $\mathrm{OD}_{600}$ values of 0.02 in $4 \mathrm{~mL}$ of sterile LB broth, and $1 \mathrm{~mL}$ of P388 solution at $25 \mathrm{mg} / \mathrm{mL}$ concentration was added to each culture ( $5 \mathrm{mg} / \mathrm{mL}$ final concentration). The ODs cultures were measured at half-hourly intervals through a $5 \mathrm{~h}$ incubation period under shaking at $280 \mathrm{RPM}$. Growth medium without bacteria was used as negative control, while positive controls were E. coli isolates grown in LB and sterile water in order to obtain equal volumes for all samples. The periodic measures were plotted to obtain a growth curve, so to determine the growth rate and generation time of Ec5FSL and Ec9FSL in presence of P388.

\subsection{Adherence Assay of E. coli on P388-Adsorbed Urinary Catheter in Static Conditions}

The biofilm-forming ability of Ec5FSL and Ec9FSL strains on $1 \mathrm{~cm}$ long segments of urinary catheter adsorbed with P388 was evaluated. Each P388-adsorbed segment was placed onto the bottom of a well of a 24-well culture plate and filled in with $250 \mu \mathrm{L}$ of strain culture, grown overnight in LB broth, adjusted to $\mathrm{OD}_{600} 0.1$, and $2.25 \mathrm{~mL}$ of LB supplemented with glucose $1 \%(w / v)$. An unadsorbed segment inoculated with each strain at the same conditions was used as positive control, while an adsorbed segment with sterile LB broth was used as negative control. Thus, the plate was incubated for $20 \mathrm{~h}$, and the biofilms grown on the segments were quantified by sonicating them in $5 \mathrm{~mL}$ of Ringer's solution, vortexing for $30 \mathrm{sec}$ and plating $100 \mu \mathrm{L}$ of serial dilutions 1:10 on Muller Hinton agar. After $18 \mathrm{~h}$ at $37^{\circ} \mathrm{C}$, colonies were enumerated to calculate average $\mathrm{CFU} / \mathrm{mL}$. The internal and external surfaces of the $1 \mathrm{~cm}$ long silicone catheter segment were considered for $\mathrm{CFU} / \mathrm{cm}^{2}$ calculation. The assay was performed in triplicate.

\subsection{Adherence Assay of E. coli on P388-Adsorbed Urinary Catheter in Dynamic Conditions}

P388 solution at $5 \mathrm{mg} / \mathrm{mL}$ concentration was made to flow inside the microfluidic channel of Bioflux (Fluxion Biosciences), and the flow was stopped to let it adsorb for $6 \mathrm{~h}$, so to obtain a P388-adsorbed microfluidic channel. As positive control, sterile water was instilled within the channel and left for $6 \mathrm{~h}$. 
After that, Ec5FSL and Ec9FSL strains was inoculated at $\mathrm{OD}_{600} 0.25$ within the channels and left to adhere for $1 \mathrm{~h}$. Nonadherent cells were pushed out of the channel towards the waste well, and the experiments were run for $15 \mathrm{~h}$ under a shear flow of $0.5 \mathrm{dyn} / \mathrm{cm}^{2}(0.05 \mathrm{~Pa})$, determined on the basis of the diameter of microfluidic channel likely to be within the physiological range of hydrodynamic conditions occurring in the human urinary tract [39]. A time-lapse recording monitored the biofilm development, by taking a sequence of frames at set intervals $(2 \mathrm{~min})$ in order to record changes that take place slowly over time, from the beginning to the end of dynamic experiments.

\subsection{Evaluation of the Stability of the P388 Adsorption on Silicone Surfaces after Urine Flow}

P388 solution at $5 \mathrm{mg} / \mathrm{mL}$ concentration was made to flow inside the microfluidic channel of Bioflux, and the flow was stopped to let it to adsorb for $6 \mathrm{~h}$, so to obtain a P388-adsorbed microfluidic channel. After that, artificial urine was made to flow within the P388-adsorbed channel for $24 \mathrm{~h}$ under a shear flow of $0.5 \mathrm{dyn} / \mathrm{cm}^{2}$. Ec5FSL was inoculated at $\mathrm{OD}_{600} 0.25$ within the channel and left to adhere for $1 \mathrm{~h}$. Nonadherent cells were pushed out of the channel towards the waste well, and the experiments were run for $15 \mathrm{~h}$ under a shear flow of $0.5 \mathrm{dyn} / \mathrm{cm}^{2}(0.05 \mathrm{~Pa})$. A time-lapse recording monitored the biofilm development, by taking a sequence of frames at set intervals $(2 \mathrm{~min})$ in order to record changes that take place slowly over time, from the beginning to the end of dynamic experiments.

\subsection{Confocal Laser Scanning Electron Microscopy}

E.coli biofilms grown within microfluidic channels were stained with LIVE/DEAD BacLight Bacterial Viability Kit (Molecular Probes) that utilizes a mixture of SYTO ${ }^{\circledR} 9$ (green-fluorescent nucleic acid stain) and propidium iodide (red-fluorescent nucleic acid stain). This kit allowed us to discriminate between live and dead cells, with intact cells staining fluorescent green, whereas damaged bacteria stained fluorescent red. In detail, a $0.85 \% \mathrm{NaCl}$ solution with $6 \mu \mathrm{M} \mathrm{SYTO} 9$ and $30 \mu \mathrm{M}$ propidium iodide was instilled within the microfluidic channel for $30 \mathrm{~min}$ at $0.4 \mathrm{dyne} / \mathrm{cm} 2$. After the staining, the channel was washed with a $0.85 \% \mathrm{NaCl}$ solution for $20 \mathrm{~min}$ at $0.4 \mathrm{dyne} / \mathrm{cm} 2$. The entire length of channel designed for Bioflux visualization, portioned in different sections, having each one an area of $0.234 \mathrm{~mm} 2$, has been observed by CLSM (Nikon mod. C1si) at 20× magnification.

\subsection{Data Analysis}

For quantitative biofilm formation assay, the cut-off OD (ODc) was defined as three standard deviations above the mean OD of the negative control. According to the defined ODc, the strains were classified on the basis of their adherence ability into the following categories: nonadherent (OD $\leq \mathrm{ODc})$, weakly adherent (ODc $<\mathrm{OD} \leq 2 \times \mathrm{ODc}$ ), moderately adherent (2ODc $<\mathrm{OD} \leq 4 \times \mathrm{ODc}$ ), and strongly adherent $(4 \times \mathrm{ODc}<\mathrm{OD})$ [40]. Results were expressed as means \pm standard deviations (s.d.) of three independent experiments.

Statistical significance was obtained by using two-tailed, unpaired Student's t-test with GraphPad Prism software (GraphPad Software Inc., La Jolla, CA, USA). Results were expressed as means \pm standard deviations (s.d.) of three independent experiments. Differences were considered as statistically significant when $p$-values were $<0.05$ or $<0.01$.

$\mathrm{OD}_{570}$ values obtained by experiments conducted by using 96-well flat-bottomed plastic tissue culture plates was also defined as $\mathrm{OD}_{570} / \mathrm{cm}^{2}$, taking into consideration that the area of the bottom of the well is $0.33 \mathrm{~cm}^{2}$.

$\mathrm{CFUs} / \mathrm{mL}$ counts arising from experiments carried out by using cut lengthwise $1 \mathrm{~cm}$ segments of urinary catheters were represented as $\mathrm{CFU} / \mathrm{cm}^{2}$, taking into consideration that the surface area of each segment is $1.65 \mathrm{~cm}^{2}$.

Recorded datasets obtained by CLSM were used for both visualization and semiquantitative analysis by counting pixels (2D) after thresholding the raw dataset. 


\subsection{Ethical Statement}

"Biobank of the Fondazione Santa Lucia, Rome-Italy has been ethically approved as a research bank by the Ethical and Protocol Review Committee, with protocol identification number "CE/PROG.796".

\section{Conclusions}

The P388-coated silicone urinary catheter shows promising potential as a safe and effective alternative to stem the relapse/recurrence of biofilm-related CAUTIs, providing more chances to treat these infections with antibiotics before the development of a mature and more resistant biofilm.

Author Contributions: Conceptualization, C.V. and I.F.; Methodology, M.S. and B.B.; Validation, M.S.; Formal Analysis, C.V. and I.F.; Investigation, M.S. and B.B.; Resources, C.V. and I.F.; Data Curation, C.V.; Writing-Original Draft Preparation C.V. and I.F.; Writing-Review and Editing, G.D. and C.V.; Visualization, M.S.; Supervision, C.V. and I.F.; Project Administration C.V.; Funding Acquisition, G.D. and C.V. and I.F. All authors have given approval to the final version of the manuscript.

Funding: Partial fundings for this study have been obtained by Gianfranco Donelli and Claudia Vuotto from Hutchison Biofilm Medical Solutions Limited, of Hutchison House, 5 Hester Road, Battersea, London, SWll 4AN, United Kingdom, and by Iolanda Francolini from Sapienza University of Rome (Project n. RP11715C785E4434).

Acknowledgments: Biological samples for this study were obtained from the Biobank of the Fondazione Santa Lucia, Rome-Italy.

Conflicts of Interest: The authors declare no conflict of interest. The sponsors had no role in the design, execution, interpretation, or writing of the study.

\section{References}

1. Foxman, B. Epidemiology of urinary tract infections: Incidence, morbidity, and economic costs. Dis. Mon. 2003, 49, 53-70. [CrossRef] [PubMed]

2. Tenke, P.; Mezei, T.; Bőde, I.; Köves, B. Catheter-associated Urinary Tract Infections. Euro. Urol. Suppl. 2017, 16, 138-143. [CrossRef]

3. Leelakrishna, P.; Karthik Rao, B. A study of risk factors for catheter associated urinary tract infection. Int. J. Adv. Med. 2018, 5, 334-339.

4. Nicolle, L.E. Urinary tract infection in long-term-care facility residents. Clin. Infect. Dis. 2000, 31, 757-761. [CrossRef]

5. Pury, J.; Mishra, B.; Mal, A.; Murthy, N.S.; Thakur, A.; Dogra, V.; Singh, D. Catheter associated urinary tract infections in neurology and neurosurgical units. J. Infect. 2002, 44, 171-175. [CrossRef]

6. Biering-Sorensen, F. Urinary tract infection in individuals with spinal cord lesion. Curr. Opin. Urol. 2002, 12, 45-49. [CrossRef]

7. Hooton, T.M.; Bradley, S.F.; Cardenas, D.D.; Colgan, R.; Geerlings, S.E.; Rice, J.C.; Saint, S.; Schaeffer, A.J.; Tambyah, P.A.; Tenke, P.; et al. Diagnosis, prevention and treatment of catheter-associated urinary tract infection in adults; 2009 international clinical practice guidelines from the Infectious Diseases Society of America. Clin. Infect. Dis. 2010, 50, 625-663. [CrossRef]

8. Flores-Mireles, A.L.; Walker, J.N.; Caparon, M.; Hultgren, S.J. Urinary tract infections: Epidemiology, mechanisms of infection and treatment options. Nat. Rev. Microbiol. 2015, 13, 269-284. [CrossRef]

9. Paterson, D.L.; Lipman, J. Returning to the pre-antibiotic era in the critically ill: The XDR problem. Crit. Care Med. 2007, 35, 1789-1791. [CrossRef]

10. Vuotto, C.; Longo, F.; Pascolini, C.; Donelli, G.; Balice, M.P.; Libori, M.F.; Tiracchia, V.; Salvia, A.; Varaldo, P.E. Biofilm formation and antibiotic resistance in Klebsiella pneumoniae urinary strains. J. Appl. Microbiol. 2017, 123, 1003-1018. [CrossRef]

11. Vuotto, C.; Grosso, F.; Longo, F.; Balice, M.P.; de Barros, M.C.; Peixe, L.; Donelli, G. Biofilm-Forming Ability and Clonality in Acinetobacter baumannii Strains Isolated from Urine Samples and Urinary Catheters in Different European Hospitals. Adv. Exp. Med. Biol. 2018, 1057, 73-83.

12. Stickler, D.J. Bacterial biofilms in patients with indwelling urinary catheters. Nat. Clin. Pract. Urol. 2008, 5, 598-608. [CrossRef] 
13. Percival, S.L.; Suleman, L.; Vuotto, C.; Donelli, G. Healthcare-associated infections, medical devices and biofilms: Risk, tolerance and control. J. Med. Microbiol. 2015, 64, 323-334. [CrossRef] [PubMed]

14. Vuotto, C.; Donelli, G. Novel Treatment Strategies for Biofilm-Based Infections. Drugs 2019, 79, $1635-1655$. [CrossRef]

15. Francolini, I.; Vuotto, C.; Piozzi, A.; Donelli, G. Antifouling and antimicrobial biomaterials: An overview. APMIS 2017, 125, 392-417. [CrossRef] [PubMed]

16. Percival, S.L.; Mayer, D.; Malone, M.; Swanson, T.; Gibson, D.; Schultz, G. Surfactants and their role in wound cleansing and biofilm management. J. Wound Care 2017, 26, 680-690. [CrossRef]

17. Alvarado-Gomez, E.; Martínez-Castañon, G.; Sanchez-Sanchez, R.; Ganem-Rondero, A.; Yacaman, M.J.; Martinez-Gutierrez, F. Evaluation of anti-biofilm and cytotoxic effect of a gel formulation with Pluronic F-127 and silver nanoparticles as a potential treatment for skin wounds. Mater. Sci. Eng. C Mater. Biol. Appl. 2018, 92, 621-630. [CrossRef] [PubMed]

18. Schroen, C.G.P.H.; Cohen Stuart, M.A.; Maarschalk, K.V.; van der Padt, A.; van't Riet, K. Influence of preadsorbed block-copolymers on protein adsorption, surface properties, layer thickness and surface coverage. Langmuir 1995, 11, 3068-3074. [CrossRef]

19. Nejadnik, M.R.; van der Mei, H.C.; Norde, W.; Busscher, H.J. Bacterial adhesion and growth on a polymer brush-coating. Biomaterials 2008, 29, 4117-4121. [CrossRef]

20. Chen, S.F.; Li, L.Y.; Zhao, C.; Zheng, J. Surface hydration: Principles and applications toward low-fouling/nonfouling biomaterials. Polymer 2010, 51, 5283-5293. [CrossRef]

21. Kozlov, M.Y.; Melik-Nubarov, N.S.; Batrakova, E.V.; Kabanov, A.V. Relationship between Pluronic Block Copolymer Structure, Critical Micellization Concentration and Partitioning Coefficients of Low Molecular Mass Solutes. Macromolecules 2000, 33, 3305-3313. [CrossRef]

22. Nejadnik, M.R.; Olsson, A.L.; Sharma, P.K.; van der Mei, H.C.; Norde, W.; Busscher, H.J. Adsorption of pluronic F-127 on surfaces with different hydrophobicities probed by quartz crystal microbalance with dissipation. Langmuir 2009, 25, 6245-6249. [CrossRef]

23. Roosjen, A.; van der Mei, H.C.; Busscher, H.J.; Norde, W. Microbial adhesion to poly (ethylene oxide) brushes: Influence of polymer chain Length and temperature. Langmuir 2004, 2, 10949-10955. [CrossRef] [PubMed]

24. Szafraniec, J.; Antosik, A.; Knapik-Kowalczuk, J.; Chmiel, K.; Kurek, M.; Gawlak, K.; Odrobińska, J.; Paluch, M.; Jachowicz, R. The Self-Assembly Phenomenon of Poloxamers and Its Effect on the Dissolution of a Poorly Soluble Drug from Solid Dispersions Obtained by Solvent Methods. Pharmaceutics 2019, 11, 130. [CrossRef] [PubMed]

25. Singh-Joy, D.; McLain, V.C. Safety assessment of poloxamers 101, 105, 108, 122, 123, 124, 181, 182, 183, 184, $185,188,212,215,217,231,234,235,237,238,282,284,288,331,333,334,335,338,401,402,403$, and 407, poloxamer 105 benzoate, and poloxamer 182 dibenzoate as used in cosmetics. Int. J. Toxicol. 2008, 27, 93-128. [PubMed]

26. Veyries, M.L.; Faurisson, F.; Joly-Guillou, M.L.; Rouveix, B. Control of staphylococcal adhesion to polymethylmethacrylate and enhancement of susceptibility to antibiotics by poloxamer 407 . Antimicrob. Agents Chemother. 2000, 44, 1093-1096. [CrossRef]

27. Treter, J.; Bonatto, F.; Krug, C.; Soares, G.V.; Baumvol, I.J.R.; Macedo, A.J. Washing-resistant surfactant coated surface is able to inhibit pathogenic bacteria adhesion. Appl. Surf. Sci. 2014, 303, 147-154. [CrossRef]

28. Wesenberg-Ward, K.E.; Tyler, B.J.; Sears, J.T. Adhesion and biofilm formation of Candida albicans on native and Pluronic-treated polystyrene. Biofilms 2005, 2, 63-71. [CrossRef]

29. Muszanska, A.K.; Nejadnik, M.R.; Chen, Y.; van den Heuvel, E.R.; Busscher, H.J.; van der Mei, H.C.; Nordea, W. Bacterial adhesion forces with substratum surfaces and the susceptibility of biofilms to antibiotics. Antimicrob. Agents Chemother. 2012, 56, 4961-4964. [CrossRef]

30. Levy, M.L.; Luu, T.; Meltzer, H.S.; Bennett, R.; Bruce, D.A. Bacterial adhesion to surfactant-modified silicone surfaces. Neurosurgery 2004, 54, 488-490, discussion 490-491. [CrossRef]

31. Nejadnik, M.R.; Engelsman, A.F.; Saldarriaga Fernandez, I.C.; Busscher, H.J.; Norde, W.; van der Mei, H.C. Bacterial colonization of polymer brush-coated and pristine silicone rubber implanted in infected pockets in mice. J. Antimicrob. Chemother. 2008, 62, 1323-1325. [CrossRef] [PubMed]

32. Hunter, R.L.; Jagannath, C.; Tinkley, A.; Behling, C.A.; Nolte, F. Enhancement of antibiotic susceptibility and suppression of Mycobacterium avium complex growth by poloxamer 331. Antimicrob. Agents Chemother. 1995, 39, 435-439. [CrossRef] [PubMed] 
33. Jeon, S.I.; Lee, J.H.; Andrade, J.D.; De Gennes, P.G. Protein-surface interactions in the presence of polyethylene oxide ii. Effect of protein size. J. Colloid Interface Sci. 1991, 142, 159-166. [CrossRef]

34. Mu, Q.; Hu, T.; Yu, J. Molecular insight into the steric shielding effect of PEG on the conjugated staphylokinase: Biochemical characterization and molecular dynamics simulation. PLoS ONE 2013, 8, e68559. [CrossRef] [PubMed]

35. Razatos, A.; Ong, Y.; Boulay, F.; Elbert, D.L.; Hubbell, J.A.; Sharma, M.M.; Georgiou, G. Force measurementsbetween bacteria and poly (ethylene glycol)-coated surfaces. Langmuir 2000, 16, 9155-9158. [CrossRef]

36. Vuotto, C.; Moura, I.; Barbanti, F.; Donelli, G.; Spigaglia, P. Subinhibitory concentrations of metronidazole increase biofilm formation in Clostridium difficile strains. Pathog Dis. 2016, 74, ftv114. [CrossRef]

37. Gyulai, G.; Magyar, A.; Rohonczy, J.; Orosz, J.; Yamasaki, M.; Bősze, S.; Kiss, É. Preparation and characterization of cationic Pluronic for surface modification and functionalization of polymeric drug delivery nanoparticles. eXPRESS Polym. Lett. 2016, 10, 216-226. [CrossRef]

38. Guilizzoni, M. Drop shape visualization and contact angle measurement on curved surfaces. J. Colloid Interface Sci. 2011, 364, 230-236. [CrossRef]

39. Aprikian, P.; Interlandi, G.; Kidd, B.A.; Le Trong, I.; Tchesnokova, V.; Yakovenko, O.; Whitfield, M.J.; Bullitt, E.; Stenkamp, R.E.; Thomas, W.E.; et al. The bacterial fimbrial tip acts as a mechanical force sensor. PLoS Biol. 2011, 9, e1000617. [CrossRef]

40. Donelli, G.; Vuotto, C.; Cardines, R.; Mastrantonio, P. Biofilm-growing intestinal anaerobic bacteria. FEMS Immunol. Med. Microbiol. 2012, 65, 318-325. [CrossRef]

Publisher's Note: MDPI stays neutral with regard to jurisdictional claims in published maps and institutional affiliations. 